\title{
30 ANOS DO DIÁRIO DE NARCISO: OBRA INAUGURAL DA NEUROLINGUÍSTICA DISCURSIVA
}

É com muita satisfação e alegria que apresentamos o volume 60 (2) da CEL que tematiza os 30 anos após o Diário de Narciso - obra que inaugurou a área de Neurolinguística no Instituto de Estudos da Linguagem.

A ideia de reunir artigos e ensaios para homenagear Maria Irma Hadler Coudry nasceu do desejo de retribuir um pouco da generosidade e do tempo que a Maza dedicou a todos nós, não só ao longo de nossas carreiras acadêmicas ou outras atividades profissionais, mas também como uma interlocutora atenta e sensível nos momentos felizes ou difíceis de nossas vidas. Nossa convivência com a Maza sempre foi constituída por fortes laços de afetividade ${ }^{1}$.

É a partir de duas grandes vertentes da reflexão teórico-metodológica de Coudry - afasia e infância - que se inspiram os trabalhos que compõem este volume, divididos em três partes apenas para evidenciar as questões que mais fortemente os relacionam e orientar o leitor ao longo da obra. A seguir, apresentamos os pontos centrais dos artigos e ensaios que expressam os diferentes olhares para os fenômenos de linguagem².

O ensaio de Maria Irma Hadler Coudry, que inicia o presente volume e que se intitula Diário de Narciso e Neurolinguística Discursiva: 30 anos depois, retoma os principais passos do percurso teórico-metodológico da autora desde seu doutoramento, em 1986, com a escrita da tese Diário de Narciso: avaliação e acompanhamento longitudinal de linguagem de sujeitos afásicos de uma perspectiva discursiva, publicada dois anos depois pela editora Martins Fontes com o título Diário de Narciso: discurso e afasia. O texto incorpora, também, sua atual reflexão, que relaciona processos linguísticos e cognitivos presentes nas afasias e nas dificuldades de crianças (com ou sem patologias), ao longo da aquisição da leitura e da escrita - tema central do projeto Neurolinguística Discursiva: afasia e infância, apoiado pelo CNPq.

Coudry discorre sobre as questões fundantes da área: a avaliação discursivamente orientada de linguagem - vista como uma prática discursiva - e

${ }^{1}$ Convivencia: palavra que exprime os princípios teórico-metodológicos e éticos dos trabalhos e que está marcada nos nomes dos grupos em que atua com afásicos e crianças: Centro de Convivência de Afásicos (CCA) e Centro de Convivência em Linguagens (CCazinho).

${ }^{2}$ A responsabilidade pelos conteúdos dos artigos e ensaios do volume é exclusiva de seus autores. Quaisquer comentários, críticas ou sugestões podem ser encaminhados para os e-mails que constam em cada um de seus textos, em nota de rodapé. 
a metodologia de tratamento dos dados, incluindo a garimpagem dos registros, a transcrição e a organização do Banco de Dados em Neurolinguística (BDN). A autora passa, em seguida, a discutir a tendência cada vez mais crescente de se patologizar crianças "normais", o que ocorre, sobretudo, pelos equívocos acerca da natureza da língua(gem) e dos processos de leitura e de escrita. Essas reflexões tiveram (e ainda têm) impacto muito relevante nas pesquisas na área, encorajando alunos e ex-orientandos na formulação de projetos inéditos, criativos e instigantes. Influenciaram, de maneira especial, as práticas com/de linguagem no campo da Fonoaudiologia, repensadas à luz das abordagens sócioculturais, com orientação qualitativa, privilegiando a interação com os sujeitos.

Sobre os desdobramentos do Diário de Narciso para a Fonoaudiologia, para o campo da Educação Especial e para a própria Linguística, recebemos as valiosas contribuições de Perottino, Padilha, Bordin \& Freire, Oliveira \& Oliveira e Mussalim que compõem, com o ensaio de Coudry, o primeiro bloco de trabalhos do volume, reunidos sob o título Neurolinguística discursiva: autoria, transmissão, revolução conceitual e metodológica.

Silvana Perottino, em Neurolinguística Discursiva e transmissão - a questão da autoria, fundamenta-se nos termos propostos por Foucault $(2009,2011)$ para reivindicar o reconhecimento da autoria para a teorização inaugurada por Coudry no Diário de Narciso e do impacto de sua transmissão para um grupo relevante de trabalhos subsequentes. Na opinião de Perottino, "a atribuição de autoria a Coudry vem do fato de seu trabalho possibilitar a ruptura com a noção generalizada de não haver mais sujeito na afasia, com a 'cegueira' generalizada à ocorrência dos processos alternativos de significação por parte dos sujeitos afásicos nas situações concretas de interlocução". A partir dos trabalhos de Coudry, segundo a autora, constata-se mudanças - inclusive éticas - na postura terapêutica de fonoaudiólogos que ingressaram na Pós-Graduação em Linguística do IEL "afetados por uma concepção teórico-metodológica centrada na indeterminação da linguagem e na realização de um trabalho linguístico dos sujeitos envolvidos na interação". Retoma, ainda, a relevância da "escrita de caso" e destaca a importância de um ambiente propício como o do IEL para a circulação dessa nova discursividade.

Na mesma direção, Anna Maria Padilha em A obra de Maria Irma Hadler Coudry: Neurolinguística Discursiva como revolução conceitual-metodológica para os estudos da Educação Especial reitera a necessidade do reconhecimento público da obra de Coudry, referindo-se a ela como uma "revolução conceitualmetodológica" e destacando a influência que teve nos estudos da Educação Especial, campo no qual Padilha atua. A autora aponta a possibilidade de transferência dos pressupostos teórico-metodológicos para a Pedagogia, lembrando o que Franchi (1986, p. XVI) afirmou no prefácio do Diário de Narciso: "há inúmeras passagens em que a transferência para situações em sala de aula é quase uma projeção geométrica". A autora retoma, no artigo, um estudo de caso para dar visibilidade ao processo de desenvolvimento de uma jovem com deficiência mental em consequência de ter nascido com agenesia parcial do corpo caloso, cujo acompanhamento foi significativamente alterado pelo contato com a ND. No exercício da dialogia, "foi possível fazer parte da evolução cognitiva e linguística 
de Bianca e antever possiblidades", com o apoio efetivo do outro. Nas palavras de Padilha: "os dados apontavam que o trabalho da/com e pela linguagem ampliaram os processos discursivos da jovem, sua participação na vida social e a compreensão do mundo que a cercava".

Sonia Bordin e Fernanda Freire propõem no texto Neurolinguística Discursiva: Contribuições para uma Fonoaudiologia na área da Linguagem que sejam reconhecidas as diferenças fundantes, no campo da linguagem, entre uma Fonoaudiologia de caráter biomédico e uma Fonoaudiologia que se beneficia de princípios teórico-metodológicos da ND. As autoras acreditam que a discussão ao retomar e ampliar o debate sobre a concepção de linguagem, sujeito e cérebro em uma abordagem sócio-histórica - pode constituir-se em uma forma de "dar voz a outros fonoaudiólogos que não se identificam com práticas corretoras ainda hegemônicas na área, e de construir um novo espaço coletivo para reinterpretar o seu papel". Para evidenciar essa prática reflexiva - que compreende o sujeito na sua relação com a linguagem, considerando questões de fala, de língua e de discurso no espaço/tempo da interlocução - as autoras retomam o estudo de caso de FS (Bordin, 2010).

Temos, em seguida, a contribuição de Elaine Oliveira e Marcus Vinicius B. Oliveira, em Neurolinguística Discursiva: Contribuições para discutir a relação entre linguagem e pobreza, que ilustra o alcance da ND como movimento que influencia trabalhos nas fronteiras entre a Fonoaudiologia, a Linguística, a Educação e a Filosofia, articulando com a ND alguns de seus princípios teóricometodológicos. O ponto central da discussão diz respeito aos equívocos recorrentes na definição da pobreza como causa direta de déficits cognitivos na população de baixa renda - e também, na direção oposta, de deficiências cognitivas gerando pobreza - quando se deveria, de fato, analisar as condições sócio-históricas que estão na base dessa relação, como a falta de acesso da população aos bens culturais, incluindo uma escola de qualidade. A literatura que analisa essa relação, segundo os autores, é pautada por resultados de avaliações metalinguísticas elaboradas na norma culta e comparadas a um normal que tem como parâmetro o ideal, o que reforça hipóteses preconceituosas e equivocadas acerca do potencial cognitivo desses sujeitos.

Fechando este primeiro bloco de trabalhos, temos o ensaio de Fernanda Mussalim intitulado A dimensão discursiva da cognição ou a dimensão cognitiva do discurso, no qual a autora reflete sobre aspectos discursivos da produção da linguagem dos pontos de vista teórico e analítico, visando "demonstrar a produtividade da proposta da Neurolinguística de tradição discursiva (ND), postulada/praticada por Maria Irma Hadler Coudry". Mussalim retoma a análise de um dado que compõe o BDN que, segundo a autora, dá visibilidade ao fato de que a ND, "que assume os processos discursivos/interacionais como princípio teórico-metodológico de base, pode lançar luzes sobre conceitos oriundos do Sociocognitivismo". A autora também se debruça, em sua argumentação, sobre o conceito de "cognição distribuída", fundamentando-se nos pressupostos teóricometodológicos da Análise do Discurso, área com a qual a ND sempre dialogou de forma produtiva. 
No segundo bloco, que intitulamos $O$ funcionamento linguístico-cognitivo nas patologias, temos cinco artigos que tematizam questões relativas às afasias, à Doença de Parkinson, ao autismo, à síndrome do X-frágil e à hidrocefalia.

O primeiro deles - Qualitative Research in Neurolinguistics: the case of Word Finding Difficulties and related phenomena - de Rosana C. Novaes Pinto, sintetiza o avanço dos estudos da autora e de seu grupo de pesquisas (GELEP) na compreensão das chamadas "Dificuldades de Encontrar Palavras" e de fenômenos relacionados (parafasias, paralexias, TOTs, dentre outros), recorrentes nas afasias e nos processos de envelhecimento (normal e patológico). Essas dificuldades foram abordados por Coudry em Diário de Narciso para evidenciar a instabilidade na seleção e na combinação de unidades linguísticas (fonemas, morfemas, sintáticosemântico-lexicais) que caracteriza cada caso.

Novaes-Pinto retoma a abordagem discursiva das WFD apresentando, inicialmente, alguns dados de "P" - um dos sujeitos afásicos que Coudry acompanhou longitudinalmente em seu doutorado e que também foi sujeito da dissertação de mestrado de Novaes-Pinto (1992). A autora enfatiza a vantagem das análises qualitativas de episódios dialógicos, que indiciam os processos subjacentes às WFD, iluminando a natureza multidimensional da palavra (Luria, 1986) e seus enlaces semânticos, fonológicos e afetivos. A opção pela produção do artigo em língua inglesa se deve à necessidade de divulgar os pressupostos teórico-metodológicos da Neurolinguística Discursiva em um circuito acadêmico e clínico mais amplo.

Julyana Nascimento e Lourenço Chacon refletem sobre a contribuição dos trabalhos de Coudry para abordar a complexidade da interrelação entre cérebro e linguagem e para problematizar dissociações correntes na literatura biomédica sobre a Doença de Parkinson (DP), tais como "linguagem" versus "fala", "fala/ linguagem" versus "aspectos motores" e ainda entre "aspectos motores" e "aspectos cognitivos" envolvidos na linguagem. Tal preocupação é sintetizada no título do trabalho - Uma abordagem não-dicotomizante das questões de linguagem na Doença de Parkinson: as hesitações.

Visando mostrar as associações entre aspectos motores e discursivos na DP, os autores analisam hesitações na conversação entre um sujeito parkinsoniano e um sujeito pesquisador. Baseados também nas ideias de Authier-Revuz, os autores concebem a hesitação como "acontecimento discursivo", relacionado ao processo de constituição do sujeito e do discurso; é entendida como forma de heterogeneidade mostrada e indicia a negociação do sujeito com os múltiplos outros constitutivos do discurso, bem como momentos de mudança de posição do sujeito; momento em que o outro discursivo saúde/doença poderia irromper/irrompe na cadeia discursiva. Observa-se, evidentemente, a presença de aspectos motores no plano articulatório da fala, mas estes se mostram submetidos a fatos discursivos que apontam mais para funcionamentos integrados do que para funcionamentos específicos nas relações entre cérebro e linguagem.

No artigo Contribuicões da Neurolinguística Discursiva para a compreensão do sujeito e da linguagem na síndrome do $x$-frágil, Michelli A. Silva analisa como essa patologia é descrita pela área médica, especialmente em relação ao 
desenvolvimento da linguagem, os efeitos de poder/saber (Foucault, 2001) - e suas implicações - produzidos pelo discurso determinístico da área médica, para a ele se contrapor com base nos postulados da ND. Para tanto, apresenta dados do processo de aquisição e uso da fala, leitura e escrita de um sujeito diagnosticado com essa síndrome, acompanhado longitudinalmente pela autora, visando identificar o que é da ordem do patológico e o que é parte do processo normal de aquisição e desenvolvimento desses processos, além do que pode estar relacionado a fatores de ordem social ou à história de vida do sujeito.

Partindo da teorização da ND - com ênfase nos estudos neuropsicológicos desenvolvidos por Vygotsky e Luria, por um lado, e os de Coudry e outros linguistas que consideram o sujeito, por outro -, Paloma Navarro em Fonoaudiologia no contexto da equoterapia com crianças autistas: uma reinterpretação a partir da Neurolinguística Discursiva propõe uma reinterpretação da prática fonoaudiológica com a linguagem no contexto da Equoterapia. Tal reinterpretação é beneficiada pelas contribuições de Wallon, Merleau-Ponty e Desjardins, cujos estudos implicam a relação entre corpo, sistema sensorial, fala e linguagem. Para justificar tal reinterpretação, a autora analisa dados do acompanhamento fonoaudiológico longitudinal de sujeitos portadores de Transtorno do Espectro Autista (TEA), com o propósito de salientar os papéis que a fonoaudióloga e o cavalo desempenham na relação com a criança.

Em Inclusão de crianças com hidrocefalia em práticas de letramento: abordagem neurolinguística, Dioneia M. Monte-Serrat articula fundamentos teórico-metodológicos da ND (Coudry, 1986/1988)e do Letramento (Tfouni, 2005), com o intuito de estudar marcas de subjetividade nas produções orais e escritas de crianças com hidrocefalia e incluir essas crianças socialmente. A hidrocefalia é uma afeç̧ão que decorre da quebra do equilíbrio do líquido cefalorraquidiano, o que deixa várias sequelas, dentre as quais o retardo neuropsicomotor que expõe a criança a uma situação de marginalização social. A autora correlaciona a teoria com as práticas metodológicas, para observar o modo como essa criança dá corpo ao exercício discursivo da linguagem, o que a constitui como sujeito. O objetivo da autora é desenvolver estratégias de avaliação adaptadas às dificuldades de funcionamento da linguagem de crianças com hidrocefalia, diferentes daquelas que se baseiam no desempenho de um sujeito ideal, uma vez que essas crianças não apresentam determinados recursos de produção e de interpretação de sentidos.

Iniciando o último bloco de trabalhos - intitulado Neurolinguística discursiva: reflexões sobre ensino-aprendizagem de crianças com ou sem patologia - temos o texto de Maria Judith Righi-Gomes, intitulado A mediação em sala de aula como construção partilhada de sentidos, que visa discutir como a ND contribui de maneira importante para se repensar temas - como a patologização, a medicalização e a mediação - que atravessam discussões sobre a prática pedagógica de professores. Para redimensionar o conceito de "mediação" em sala de aula, relacionando o funcionamento cerebral, o simbólico e o histórico, a autora relata uma atividade de ciências em uma sala de oitavo ano do Ensino Fundamental II, na qual a grande maioria dos alunos apresentava dificuldades de leitura e de escrita que interferiam de forma relevante na compreensão de 
conceitos. Segundo a autora, ao se reconhecer no aluno um sujeito de linguagem e, portanto, dependente das relações que estabelece em seu meio, a construção partilhada de sentidos atua como um contradispositivo (Agamben, 2009) frente às metodologias padronizantes, implantadas por políticas públicas ainda vigentes na escola.

Patrícia Aquino apresenta em seu artigo Onde está o déficit? - Polêmica em torno da dislexia um breve histórico da gênese da polêmica em torno da chamada "dislexia" e analisa enunciados e materiais produzidos por profissionais que se consideram especialistas em alfabetização. A autora justifica, do ponto de vista linguístico, alguns erros ortográficos de aprendizes de escrita - muitos dos quais, inadvertidamente, são tomados como sintomas de dislexia - e analisa um dado produzido por uma criança em processo de aquisição de leitura e de escrita, acompanhada por ela no Centro de Convivência de Linguagens (CCazinho), do IEL/Unicamp, seguindo os postulados de Coudry (1986/1988).

O texto de Monica Caron, As relações da Neurolinguística Discursiva com os familiares das crianças em processo de aprendizado de escrita e leitura, apresenta uma importante e atual questão, que relaciona duas instituições em transformação: a família e a escola. Para tanto, relata o trabalho que realizou com familiares de crianças que frequentam o Centro de Convivência de Linguagens (CCazinho), IEL/Unicamp, com base em pressupostos teóricos da ND. A autora explicita, por um lado, a diversidade de ordenações familiares, as desigualdades culturais e materiais de grande parte dessas famílias e, de outro, a ineficiência da gestão escolar no acompanhamento de crianças com ritmos distintos ou particulares, culminando em fracassos. Defende, assim, que acontecimentos implicados na construção de uma parceria entre as duas instituições em benefício da criança/ aluno podem interferir positivamente nas políticas públicas educacionais.

Finalizando as contribuições ao volume, Sirio Possenti presenteia os leitores com uma (carinhosa) resenha - Em Diário de Narciso... ainda -, que retoma, além de alguns pressupostos teórico-metodológicos do Diário de Narciso, o contexto da produção da obra. Tendo sido colega de Coudry no Departamento de Linguística do IEL e acompanhado o nascimento e o percurso de suas reflexões, o autor destaca a coragem de Coudry para se opor ao discurso biologizante das afasias e ao método experimental quantitativo, ainda hegemônicos na área. Possenti ressalta a necessidade de uma ampla divulgação da obra de Coudry, a fim de combater preconceitos infundados que ainda vigoram nas escolas e nas clínicas.

Agradecemos imensamente a todos os autores, pela dedicação ao longo do processo de produção dos artigos. Os diálogos, ao nosso ver, foram muito produtivos e esclarecedores . Nosso muito obrigada também à Profa. Maria Laura Sabinson - a Lalau - que, atendendo ao nosso pedido, editou uma foto da Maza de que todos gostamos muito.Agradecemos, especialmente, ao Setor de Publicações do IEL, responsável pela editoração e publicação do volume, por todo o apoio e competência profissional, sobretudo ao Esmeraldo e ao Nivaldo.

Por fim, acreditamos que o conjunto de textos apresentado ofereça um panorama do alcance das ideias de Coudry e de seus desdobramentos - ou de seus 
diferentes caminhos $^{3}$ - nas mais diversas áreas. Esperamos que este volume da CEL propicie aos seus leitores - aos que conhecem e aos que não conhecem a sua obra - momentos prazerosos de reflexão e que motivem novos diálogos.

Rosana do Carmo Novaes Pinto Fernanda Maria Pereira Freire

\footnotetext{
${ }^{3}$ Caminhos: outra palavra empregada com frequência pela Maza, que pode expressar tanto os processos alternativos/criativos de significação desenvolvidos pelo trabalho dos sujeitos com/sobre a linguagem, quanto o os efeitos que a própria ND pode provocar na teorização, na formação e na atuação de profissionais com diferentes perfis. Não é por acaso que uma de suas obras mais recentes tem como título: Caminhos da Neurolinguística Discursiva: teorização e práticas com a linguagem (Mercado de Letras, 2010).
} 


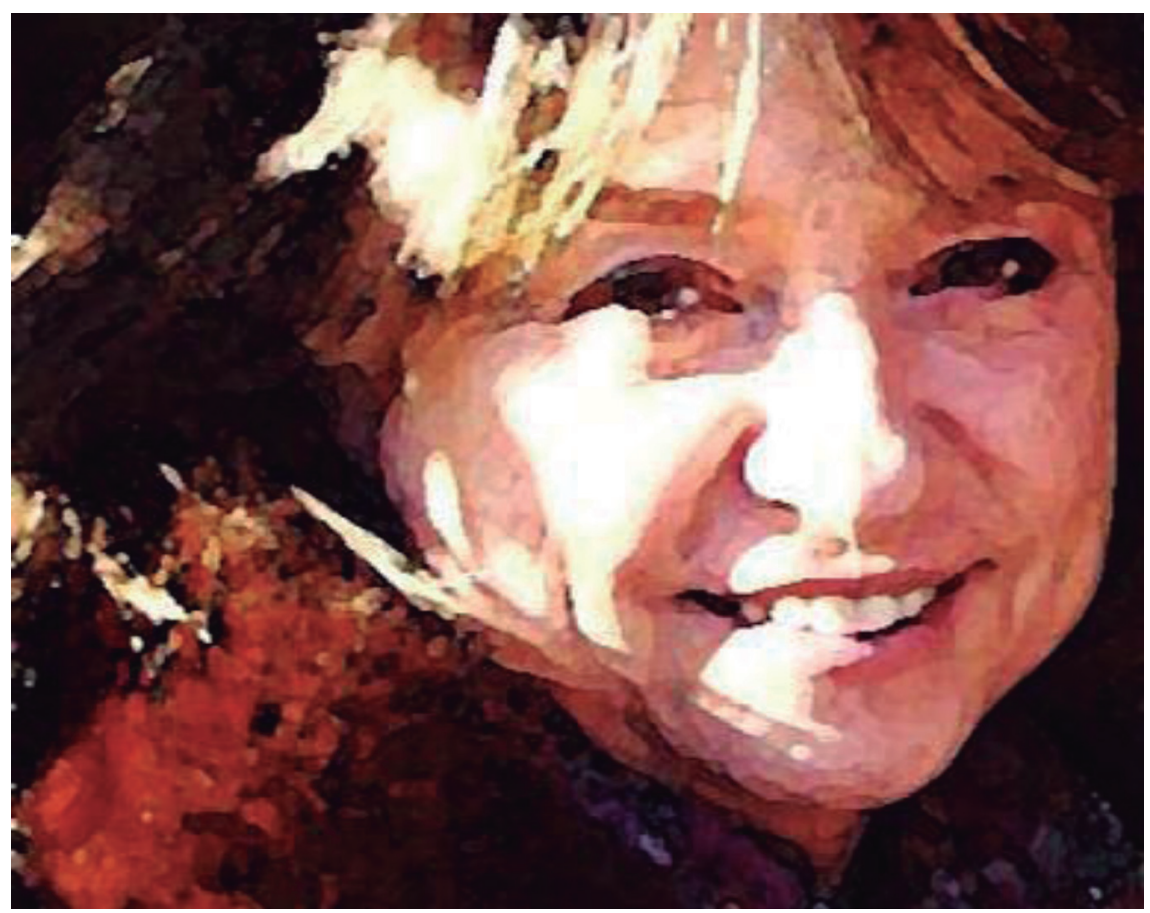

